\title{
Selection of Optimum Parameters in Non Conventional Machining of Metal Matrix Composite
}

\author{
K.L. Senthil Kumar, ${ }^{1, *}$ R. Sivasubramanian, ${ }^{2}$ K. Kalaiselvan ${ }^{1,3}$ \\ ${ }^{1}$ Dept. of Mechanical Engineering, Bannari Amman Institute of Technology, Sathyamangalam - \\ 638401, Erode District, Tamilnadu, India \\ ${ }^{2}$ Dept. of Mechanical Engineering, Coimbatore Institute of Technology, Coimbatore, \\ Tamilnadu, India \\ ${ }^{3}$ Dept. of Production Engineering, Madras Institute of Technology, Chennai, Tamilnadu, India
}

Received 13 February 2009; accepted 1 July 2009

\begin{abstract}
Aluminium metal matrix composites (AMMCs) are now gaining their usage in aerospace and automotive industries. Because of their inherent nature, difficult to machine, they find very little applications in other sectors. Even non traditional processes like Laser Jet Machining and Electro Discharge Machining result in significant sub surface damage to the work. In this paper, an attempt is made to machine the $\mathrm{A} 356 / \mathrm{SiC}_{\mathrm{p}}$ composite work material using Electro Chemical Machining process. Silicon carbide with an average particle size of 40 microns is tried in three different proportions, namely $5 \%, 10 \%$ and $15 \%$ by weight. Taguchi's $\mathrm{L}_{27}$ orthogonal array is chosen to design the experiments and 54 trials are conducted to study the effect of various parameters like applied voltage, electrolyte concentration, feed rate and percentage reinforcement on maximizing the material removal rate. ANOVA results have shown that all the four selected factors are significant and from the $\mathrm{S} / \mathrm{N}$ graph the optimum level of each factor is chosen. A mathematical model is also developed using the regression method. Confirmation experiment is conducted and found that the data obtained have close match with the data predicted using the model.
\end{abstract}

Keywords: Metal Matrix Composite, Electro Chemical Machining, Taguchi, ANOVA, Material Removal Rate.

\section{Introduction}

Metal Matrix Composites (MMCs) possess higher stiffness and specific strength than that of conventional structural materials that are used in aerospace and automotive industries. MMCs generally consist of a light weight metal as matrix

\footnotetext{
*Corresponding author. E-mail address: senthil_kl@rediffmail.com
} 
element, and the fibers, whiskers or particles as reinforcing element. Reinforcement helps in improving the material properties which otherwise the metal alone doesn't have. The mechanical characteristics of the material can be altered by selecting the right matrix material, right reinforcement material as well as the quantity to be embedded into the matrix. Metal matrix composites show considerable improvement in stiffness, elastic limit, tensile strength, and fatigue strength, when compared to the matrix material. Apart from this, they also possess high creep strength even at elevated temperatures and adequate thermal fatigue resistance. The commonly used metallic matrix includes aluminium alloys, and widely used reinforcements are $\mathrm{SiC}$ and $\mathrm{Al}_{2} \mathrm{O}_{3}$ [1]. Electro chemical machining (ECM) is an effective method for machining large variety of products for automotive, defense, and medical industries. Even though the complete nature of the process is not fully understood, the benefits are being increasingly recognized by aircraft and aerospace industries. This method has proved better than the conventional ones, those involving physical action of cutting tools in machining of MMCs, and there is neither tool wear nor subsurface damage when operated under correct conditions.

\section{Literature on machining of MMC}

Aluminium alloys reinforced with hard particles like $\mathrm{SiC}$ are becoming most advantageous among others because of their low cost. Their wide spread applications are primarily hindered by their difficult to cut nature. A detailed study of different tooling systems has been made by Manna and Bhattacharya [2]. Results showed that the rotary circular tooling exhibits good wear resistance, the rhombic fixed tool is effective at high speed and low depth of cut, the fixed circular tooling provides better results at high depth of cut, and high speed and RCT produce low surface finish. The SiC particles in MMCs are harder than tungsten carbide and that warrants the need for poly crystalline diamond (PCD) in turning operations, and the effect of cutting parameters is studied by Paulo Davim [3]. Tomac and Tonnessen [4] have reported that PCD tools are better than carbide tools (K10), but results in high machining cost. Hung et al. [5] have concluded that the cubic boron nitride and diamond tools, being the best among other conventional materials, suffer from high tool cost and restricted shape. Ding et al. [6] have claimed that PCD tools are better than PCBN ones because of their high resistance to abrasion and fracture. But according to Brun and Lee [7] the PCD also has relatively shorter tool life at moderate speed. Teti [8] found that the tools coated with diamond using CVD may be superior to PCD in machining the brake drum made of aluminium MMC. According to his findings, the machinability is critically affected by the reinforcement and matrix hardness rather than cutting parameters. Machining MMCs with different nonconventional methods have been carried out by Muller and Monaghan $[9,10]$. Their investigations concluded that Electro Discharge Machining has produced relatively small subsurface damage in the cut surface, and Laser machining, though suitable for high feed rates, resulted in significant thermal induced micro structural changes, while Abrasive Water Jet machining can be applied for only rough cut applications, as slotted edge damage is observed in the latter. Another 
similar result is depicted by W S Lau et al. [11] who machined MMC using EDM and laser cutting operations. Currently all MMCs are considered appropriate material in automobile engine moving parts, where more weight reduction is expected. In most cases the parts have to undergo machining like drilling, milling, and threading operations [12].

ECM is an anodic dissolution process, in which the anode work piece is dissolved according to the Faraday's law. The dissolved materials are flushed out by the electrolyte. Sodium chloride $(\mathrm{NaCl})$ and Sodium nitrate $\left(\mathrm{NaNO}_{3}\right)$ are the commonly used electrolytes in electrochemical machining. Investigations made by Joao Cirilo da Silva et al. [13] showed that $\mathrm{NaCl}$ results with higher material removal rate than $\mathrm{NaNO}_{3}$. They also observed that feed rate and voltage control the MRR for both solutions. Hewidy [14] has suggested that keeping the electrolyte flow rate more than 3 liters per minute will avoid sparking. Short pulses can be effectively used to achieve higher degree of localized dissolution, according to the findings reported by Rajurkar et al. [15]. Rajurkar and Zhu [16] have done work in improving machining accuracy by using orbital electrode and achieved significant improvement. Zhu et al. [17] have proposed a method of estimating electrode shape in electro chemical manufacturing process. Machining of metal matrix composite material using electrochemical machining is successfully reported by Hihara et al. [18]

Though a good number of researches on machining of composite materials have been made, no literature reveals the selection of optimum parameters in machining MMC using electro chemical machining. The purpose of the present study, therefore, is to: (a) produce particle-reinforced metal matrix composites by stir casting method; (b) machining MMC using electrochemical method based on Taguchi's designed experiments; and (c) determining significant parameters and developing a mathematical model.

\section{Experimental work}

In this experimental work of identifying optimum parameters, MMC of type $\mathrm{A} 356 / \mathrm{SiC}_{\mathrm{p}}$ reinforced with $5 \%, 10 \%$, and $15 \% \mathrm{SiC}$ by wt. are manufactured and used as work materials. Based on the Taguchi's orthogonal array chosen, designed experiments are conducted on an electrochemical machining setup.

\section{Production of $M M C$}

The materials are prepared using stir casting method. The aluminium alloy is heated through $800^{\circ} \mathrm{C}$ for 90 minutes in the muffle furnace. Hot $\mathrm{SiC}$ powder at $1000{ }^{\circ} \mathrm{C}$ is then gradually mixed with the molten aluminium alloy and stirred for 15 minutes to make the mixture homogeneous. The average diameter of the $\mathrm{SiC}$ particle size is around 40 microns. The mixture is poured into a preheated metal mould kept at $350-400{ }^{\circ} \mathrm{C}$ and allowed to solidify. The work material of $\varnothing 25$ $\mathrm{mm}$ and $175 \mathrm{~mm}$ length is removed from the mould after 3 hours. 


\section{Plan of experiments (Taguchi's techniques)}

Experiments are conducted based on Taguchi's method with four factors at three levels each. The values taken by a factor are termed to be levels. The factors to be studied and their levels chosen are detailed in the Table 1.

Table 1. Factors and levels.

\begin{tabular}{|lccc|}
\hline \multicolumn{1}{|c}{ Factor } & \multicolumn{3}{c|}{ Levels } \\
& $\mathbf{1}$ & $\mathbf{2}$ & $\mathbf{3}$ \\
Voltage (Volts) & 5 & 10 & 15 \\
Feed rate $(\mathrm{mm} / \mathrm{min})$ & 0.2 & 0.4 & 0.6 \\
Concentration $(\mathrm{gm} / \mathrm{L})$ & 50 & 100 & 30 \\
SiC percentage $(\mathrm{wt} \mathrm{\% )}$ & 15 & 10 & 5 \\
\hline
\end{tabular}

It is planned to study the effect of four main factors and four interactions. The $\mathrm{L}_{27}$ $\left(3^{13}\right)$ orthogonal array which provides the required number of degrees of freedom is selected. This array consists of 27 rows (26 degrees of freedom) each representing an experiment with 13 columns at three levels. The columns are assigned with factors and interactions as given by the appropriate linear graph, as depicted in Fig. 1.

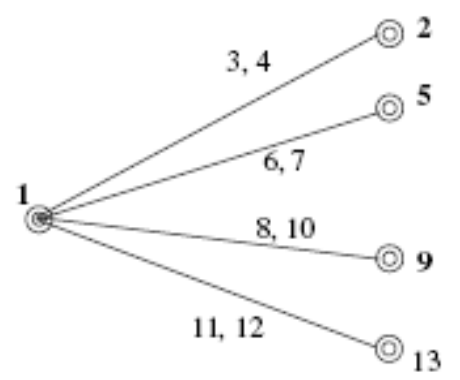

Figure 1. Linear graph for L27 (313) OA.

The plan of experiments is made of 27 tests (array rows) in which the first column is assigned to the voltage (V), the second column to the feed rate (f), the fifth column to the electrolyte concentration $(\mathrm{C})$, the ninth column to the percentage of $\mathrm{SiC}_{\mathrm{p}}(\mathrm{p})$, the remaining are assigned to the interactions. The response to be studied is the material removal rate (MRR) and the tests are replicated, resulting in a total of 54 tests, allowing for the analysis of the variance of the results. Table 2 shows the standard table of the $\mathrm{L}_{27} \mathrm{OA}$.

\section{Performing experiments}

The specimens of $\varnothing 25 \mathrm{~mm}$ and $25 \mathrm{~mm}$ length are prepared and the flat surfaces are ground for better surface finish. Machining tests of the specimens are carried out on electro chemical machining set up with constant flow rate of electrolyte. Aqueous solution of sodium chloride $(\mathrm{NaCl})$ is used as electrolyte. Electrolyte flow rate is fixed as 5 liters per minute and an inter electrode gap of $0.3 \mathrm{~mm}$ is maintained for all the tests. The other machining conditions are furnished in the Table 3. 
Table 2. Standard $\mathrm{L}_{27}\left(3^{13}\right)$ orthogonal array.

\begin{tabular}{|cccccccccccccc|}
\hline Trial & $\mathbf{1}$ & $\mathbf{2}$ & $\mathbf{3}$ & $\mathbf{4}$ & $\mathbf{5}$ & $\mathbf{6}$ & $\mathbf{7}$ & $\mathbf{8}$ & $\mathbf{9}$ & $\mathbf{1 0}$ & $\mathbf{1 1}$ & $\mathbf{1 2}$ & $\mathbf{1 3}$ \\
1 & $\mathbf{1}$ & $\mathbf{B}$ & $\mathbf{A x B}$ & $\mathbf{A x B}$ & $\mathbf{C}$ & $\mathbf{A x C}$ & $\mathbf{A x C}$ & $\mathbf{A x D}$ & $\mathbf{D}$ & $\mathbf{A x D}$ & $\mathbf{B x C}$ & $\mathbf{B x C}$ & $\mathbf{e}$ \\
2 & 1 & 1 & 1 & 1 & 1 & 1 & 1 & 1 & 1 & 1 & 1 & 1 & 1 \\
3 & 1 & 1 & 1 & 1 & 2 & 2 & 2 & 2 & 2 & 2 & 2 & 2 & 2 \\
4 & 1 & 2 & 2 & 2 & 1 & 3 & 3 & 3 & 3 & 3 & 3 & 3 & 3 \\
5 & 1 & 2 & 2 & 2 & 2 & 2 & 1 & 2 & 2 & 2 & 3 & 3 & 3 \\
6 & 1 & 2 & 2 & 2 & 3 & 3 & 3 & 1 & 3 & 3 & 1 & 1 & 1 \\
7 & 1 & 3 & 3 & 3 & 1 & 1 & 1 & 3 & 3 & 1 & 2 & 2 & 2 \\
8 & 1 & 3 & 3 & 3 & 2 & 2 & 2 & 1 & 1 & 1 & 2 & 2 & 2 \\
9 & 1 & 3 & 3 & 3 & 3 & 3 & 3 & 2 & 2 & 2 & 1 & 1 & 3 \\
10 & 2 & 1 & 2 & 3 & 1 & 2 & 3 & 1 & 2 & 3 & 1 & 2 & 3 \\
11 & 2 & 1 & 2 & 3 & 2 & 3 & 1 & 2 & 3 & 1 & 2 & 3 & 1 \\
12 & 2 & 1 & 2 & 3 & 3 & 1 & 2 & 3 & 1 & 2 & 3 & 1 & 2 \\
13 & 2 & 2 & 3 & 1 & 1 & 2 & 3 & 2 & 3 & 1 & 3 & 1 & 2 \\
14 & 2 & 2 & 3 & 1 & 2 & 3 & 1 & 3 & 1 & 2 & 1 & 2 & 3 \\
15 & 2 & 2 & 3 & 1 & 3 & 1 & 2 & 1 & 2 & 3 & 2 & 3 & 1 \\
16 & 2 & 3 & 1 & 2 & 1 & 2 & 3 & 3 & 1 & 2 & 2 & 3 & 1 \\
17 & 2 & 3 & 1 & 2 & 2 & 3 & 1 & 1 & 2 & 3 & 3 & 1 & 2 \\
18 & 2 & 3 & 1 & 2 & 3 & 1 & 2 & 2 & 3 & 1 & 1 & 2 & 3 \\
19 & 3 & 1 & 3 & 2 & 1 & 3 & 2 & 1 & 3 & 2 & 1 & 3 & 2 \\
20 & 3 & 1 & 3 & 2 & 2 & 1 & 3 & 2 & 1 & 3 & 2 & 1 & 3 \\
21 & 3 & 1 & 3 & 2 & 3 & 2 & 1 & 3 & 2 & 1 & 3 & 2 & 1 \\
22 & 3 & 2 & 1 & 3 & 1 & 3 & 2 & 2 & 1 & 3 & 3 & 2 & 1 \\
23 & 3 & 2 & 1 & 3 & 2 & 1 & 3 & 3 & 2 & 1 & 1 & 3 & 2 \\
24 & 3 & 2 & 1 & 3 & 3 & 2 & 1 & 1 & 3 & 2 & 2 & 1 & 3 \\
25 & 3 & 3 & 2 & 1 & 1 & 3 & 2 & 3 & 2 & 1 & 2 & 1 & 3 \\
26 & 3 & 3 & 2 & 1 & 2 & 1 & 3 & 1 & 3 & 2 & 3 & 2 & 1 \\
27 & 3 & 3 & 2 & 1 & 3 & 2 & 1 & 2 & 1 & 3 & 1 & 3 & 2 \\
\hline
\end{tabular}

Table 3. Experimental conditions.

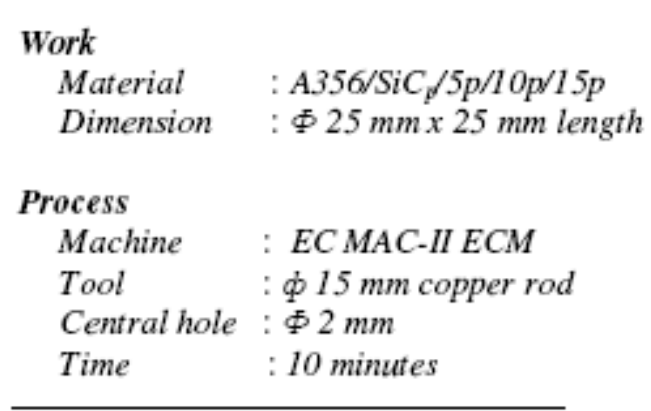

To calculate the metal removal rate, the following equation, which is slightly modified from the one used by Joao Cirilo da Silva et al. [13], is considered:

$$
M R R=\frac{\left(m_{f}-m_{i}\right)}{t}
$$

where $\mathrm{m}_{\mathrm{i}}, \mathrm{m}_{\mathrm{f}}$ are masses (in $\mathrm{gm}$ ) of the work material before and after machining, respectively, and ' $\mathrm{t}$ ' is the time of machining in minutes. An electronic weighing machine with an accuracy of $1 \mathrm{mg}$ is used to weigh the material. 


\section{Results and discussions}

The conventional way of looking into the averages of results to know the desirable factor levels doesn't account the variability of the results within the trials. Hence signal-to-noise $(\mathrm{S} / \mathrm{N})$ ratio is used considering the material removal rate as the performance index. Analysis of variance (ANOVA) is a statistical tool which, based on the experimental values, will help to infer some important conclusions. The level of significance of influence of a factor or interaction of factors on a particular output response could be revealed by this method.

\section{Signal-to-noise ratio}

The $\mathrm{S} / \mathrm{N}$ ratio for MRR is calculated using higher-the-better criterion, which is given by Taguchi [19] as:

$$
S / N=-10 \log \left[\frac{1}{n} \sum \frac{1}{y^{2}}\right]
$$

where $\mathrm{y}$ is the observed data and $\mathrm{n}$ is the number of observations.

From the orthogonal array used, it is possible to get the effects of each factor at different levels. For instance, the average $\mathrm{S} / \mathrm{N}$ ratio for the factor $\mathrm{A}$ at levels 1,2 , and 3 can be obtained by calculating the mean of the $\mathrm{S} / \mathrm{N}$ ratios for the trials 1-9, 10-18, and 19-27, respectively. The mean S/N ratio for each level of all other factors is computed in similar fashion. All these values are summarized and shown in the Table 4 known as response table for $\mathrm{S} / \mathrm{N}$ ratio.

Table 4. S/N response table for MRR.

\begin{tabular}{|lccccc|}
\hline \multicolumn{1}{|c}{ Parameters } & \multicolumn{3}{c}{ S/N ratio (dB) } & Max - Min & Rank \\
& Level 1 & Level 2 & Level 3 & & \\
Voltage & 19.42 & 17.77 & 17.67 & 1.75 & 3 \\
Feed rate & 18.91 & 19.54 & 16.41 & 3.13 & 1 \\
Electrolyte concentration & 17.12 & 19.74 & 18.01 & 2.62 & 2 \\
SiC content & 17.33 & 18.68 & 18.85 & 1.52 & 4 \\
\hline
\end{tabular}

The mean $\mathrm{S} / \mathrm{N}$ ratio $=18.29 \mathrm{~dB}$

The response table shows the average of selected characteristics for each level of the factor. This table includes the ranks based on the delta statistics, which compare the relative value of the effects. It is the difference between the highest and lowest averages for the factor chosen. Rank starting from 1 is assigned in the descending order of the delta values.

The S/N graph for voltage (Fig. 2a) seems to be more robust at low voltage than at its higher levels, as the increase in voltage resulted in frequent occurrence of sparks which may affect the robustness of the process. From Fig. (2b) it is understood that the feed rate is good at its middle level, because the material removal rate is inadequate to provide enough inter electrode gap at higher feed rates under constant electrolyte flow rate. In the case of electrolyte concentration 
(Fig. 2c), the higher concentration of the electrolyte produces better result than the other two levels. Reason may be attributed to the increasing number of ions at higher concentration compared to the other two levels. This is the first time to consider SiC content as one of the study parameters in ECM. From Fig. 2(d) it is obvious that the lowest content of $\mathrm{SiC}$ produces better material removal rate. Silicon carbide is inactive in the chemical reaction that dissolves the matrix material. Addition of this reduces the volume of matrix material and this may be the reason for the above finding. The $\mathrm{S} / \mathrm{N}$ curves drawn indicate that the voltage at its first level $(5 \mathrm{~V})$, feed rate at its second level $(0.4 \mathrm{~mm} / \mathrm{min})$, electrolyte concentration at its second level $(100 \mathrm{gm} / \mathrm{L})$, and $\mathrm{SiC}$ of $5 \mathrm{wt} \%$, are the optimum levels for maximizing MRR.

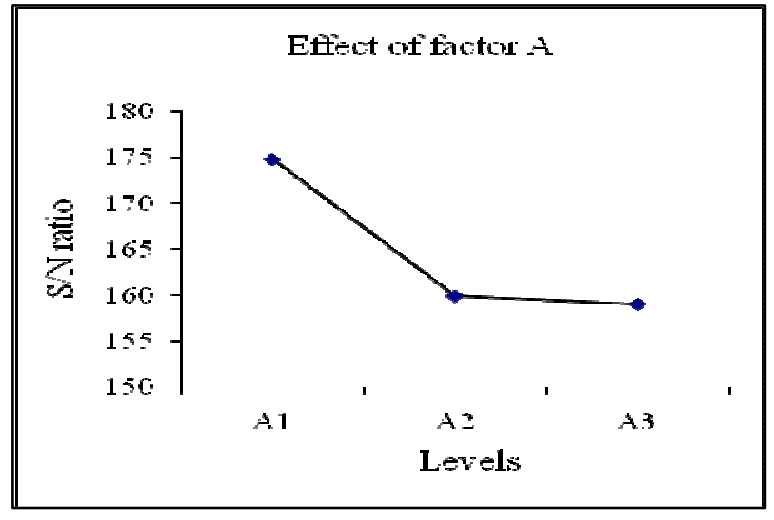

(Fig. 2a. Effect of voltage.)

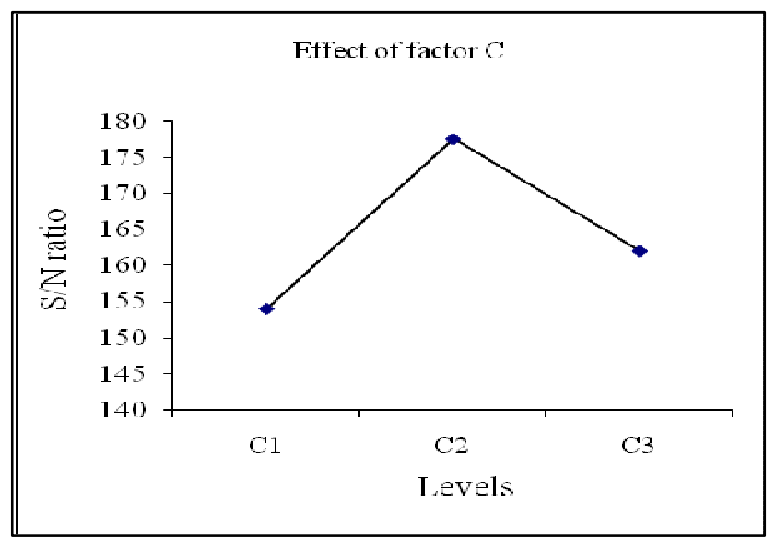

(Fig. 2c. Effect of electrolyte concentration.)

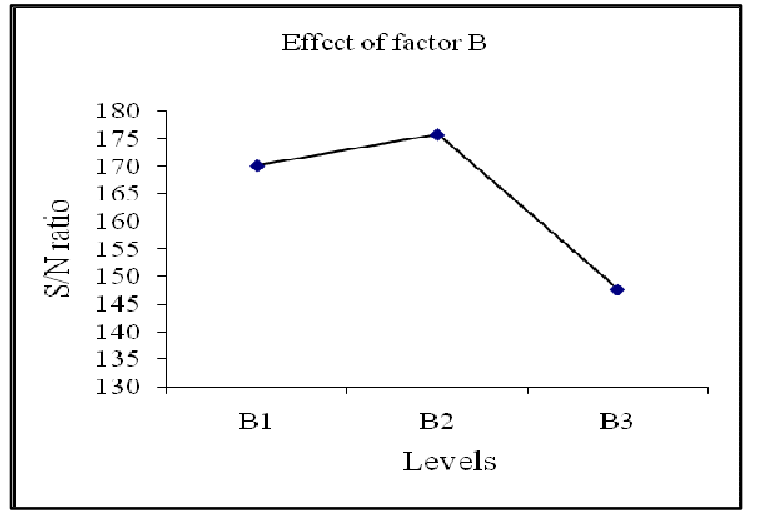

(Fig. 2b. Effect of feed rate.)

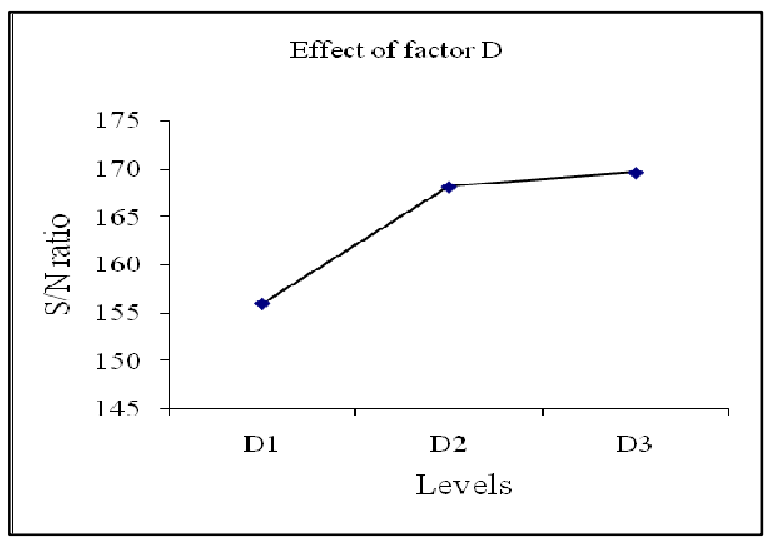

(Fig. 2d. Effect of reinforcement.)

Figure 2. Effect of main factors on material removal rate.

\section{Analysis of variance}

ANOVA is performed to identify the parameters and interactions that influence the output variable. Table 5 shows the ANOVA result for the material removal rate of $\mathrm{Al}-\mathrm{SiCp} \mathrm{MMC}$ under electro chemical machining. The F-ratio, which is 
used to measure the significance of factor at the desired significance level, is the ratio between variance due to the effect of a factor and variance due to error term.

Table 5. Results of ANOVA.

\begin{tabular}{|c|l|c|c|c|c|c|}
\hline Symbol & Parameters & SoS & dof & MSS & F & $\begin{array}{c}\text { \% } \\
\text { Cont }\end{array}$ \\
\hline A & Voltage & 17.45 & 2 & 8.73 & $53.43^{*}$ & 14.1 \\
\hline B & Feed rate & 49.20 & 2 & 24.60 & $150.61^{*}$ & 40.1 \\
\hline C & Concentration & 31.94 & 2 & 15.97 & $97.77^{*}$ & 26.0 \\
\hline D & SiC \% & 12.54 & 2 & 6.27 & $38.39^{*}$ & 10.0 \\
\hline A x B & Interaction & 2.93 & 4 & 0.73 & $4.49^{*}$ & 1.9 \\
\hline A x C & Interaction & 0.83 & 4 & 0.21 & 1.27 & 0.1 \\
\hline B x C & Interaction & 1.22 & 4 & 0.30 & 1.86 & 0.5 \\
\hline A x D & Interaction & 0.91 & 4 & 0.23 & 1.40 & 0.2 \\
\hline e & Error & 4.74 & 29 & 0.16 & --- & 7.1 \\
\hline Total & & 121.76 & 53 & --- & --- & 100.0 \\
\hline
\end{tabular}

$* \mathrm{~F}_{0.05,4,29}=2.70 ; \mathrm{F}_{0.05,2,29}=3.33$

From Table 5 results it is obvious that all the selected factors have statistical and physical significances on the material removal rate during machining of composite at $95 \%$ confidence level. This has agreement with the results of Joao Cirilo da Silva Neto et al. [13] and for the effect of reinforcement no reference is available so far. Since the interaction A x B seems to be significant, the optimum levels for factors A and B should be considered from their two way interaction table. The maximum value is found for the combination of $A_{1} B_{2}$ which is the same as the results obtained from $\mathrm{S} / \mathrm{N}$ curve. From the ANOVA table it is clearly observed that the feed rate of electrode $(40 \%)$, electrolyte concentration $(26 \%)$, applied voltage (14\%) and percentage of reinforcement $(10 \%)$, have significant and physical influence on the selected response. Also, it is observed that the error associated to the ANOVA for material removal rate is $7 \%$.

\section{Equation of the model}

To develop a mathematical model of the data collected, the linear regression analysis of the data is done using the software XLSTAT. The equation obtained is:

$\mathrm{R}=0.769$

$$
\mathrm{y}=11.82905-0.17106 * \mathrm{a}-5.54028 * \mathrm{~b}+3.02628 \mathrm{E}-02 * \mathrm{c}-0.12683 * \mathrm{~d}
$$

where $y$ is the response variable, i.e., material removal rate, and $\mathrm{a}-$ the voltage, $\mathrm{b}$ - the feed rate, $\mathrm{c}$ - the electrolyte concentration, and $\mathrm{d}$ - the percentage of reinforcement. 


\section{Confirmation test}

Confirmation test is carried out to verify the accuracy of the model developed. Table 6 shows the levels of each factor chosen to conduct the confirmation experiment.

Table 6. Levels of factors for confirmation test.

\begin{tabular}{|l|c|c|c|}
\hline & Level CT1 & Level CT2 & Level CT3 \\
\hline Voltage $(\mathrm{V})$ & 6 & 9 & 12 \\
\hline Feed rate $(\mathrm{mm} / \mathrm{min})$ & 0.2 & 0.3 & 0.4 \\
\hline Electrolyte concentration $(\mathrm{gm} / \mathrm{L})$ & 40 & 60 & 80 \\
\hline SiC percentage $(\mathrm{wt} \%)$ & 5 & 10 & 15 \\
\hline
\end{tabular}

Table 7. Confirmation test results for MRR.

\begin{tabular}{|ccccc|}
\hline Trial No. & Experiment & Model & Difference & \% error \\
\hline c1 & 8.85 & 9.08 & 0.23 & 2.63 \\
c2 & 9.21 & 9.09 & 0.12 & 1.25 \\
c3 & 9.03 & 8.65 & 0.38 & 4.21 \\
c4 & 9.10 & 9.74 & 0.64 & 7.03 \\
c5 & 7.96 & 8.11 & 0.15 & 1.86 \\
\hline
\end{tabular}

The experimental data obtained are compared with the values predicted by the developed model and presented in Table 7. The maximum percentage of error from the table is $6.87 \%$ and minimum is $1.25 \%$. It is observed that the model has an agreeable degree of approximation.

\section{Conclusion}

In the present study, four factors are considered and out of which three factors are linked with the process (ECM) and the fourth one namely 'content of SiC' is associated with the product machined. Put together they are mentioned as process cum product parameters.

Aluminium metal matrix composite is prepared using stir cast method. ECM process is used to machine the composite and process cum product parameters are experimented to obtain an optimum level in achieving high material removal rate. The following conclusions are arrived:

- Inclusion of silicon carbide particle has significant influence on MRR.

- Among the three process parameters, feed rate (40\%) influences highly the response characteristic, followed by concentration of electrolyte $(26 \%)$ and by the applied voltage (14\%).

- $\quad$ From the $\mathrm{S} / \mathrm{N}$ curves drawn it is observed that the optimum level, of the factors selected, which will produce maximum MRR is A1B2C2D3 and the value obtained is $12.86 \mathrm{mg} / \mathrm{min}$.

- A mathematical model is developed using linear regression with the help of software tool. 


\section{Acknowledgement}

Authors wholeheartedly acknowledge Dr K Ragukandan, Head, Department of Manufacturing Engineering, Annamalai University, for granting permission to conduct the experiments on ECM setup.

\section{References}

1. J.P. Davim, Journal of Materials Processing Technology 128 (2002) 100105.

2. A. Manna, B. Bhattacharya, Journal of Materials Processing Technology 123 (2002) 476-482.

3. J.P. Davim, Journal of Materials Processing Technology 132 (2003) 340344.

4. $\quad$ N. Tomac, K. Tonnessen, Annals of CIRP 41 (1992) 55-58.

5. N.P. Hung, F.Y.C. Boey, K.A. Khor, Y.S. Phua, H.F. Lee, Journal of Materials Processing Technology 56 (1996) 966-977.

6. X. Ding, W.Y.H. Liew, X.D. Liu, Wear 259 (2005) 1225-1234.

7. M.K. Brun, M. Lee, Wear 104 (1985) 21-29.

8. R. Teti, CIRP Annals - Manufacturing Technology 51-2 (2002) 611-634.

9. F. Muller, J. Monaghan, International Journal of Machine Tools \& Manufacture 40 (2000) 1351-1366.

10. F. Muller, J. Monaghan, Journal of Materials Processing Technology 118 (2001) 278-285.

11. W.S. Lau, T.M. Yue, T.C. Lee, W.B. Lee, Journal of Materials Processing Technology 48 (1995) 199-205.

12. K. Weinert, D. Biermann, S. Bergmann, Annals of CIRP 56 (2007) 105-108.

13. J.C.S. Neto, E.M. Silva, M.B. Silva, Journal of Materials Processing Technology 179 (2006) 92-96.

14. M.S. Hewidy, Journal of Materials Processing Technology 160 (2005) 348353.

15. K.P. Rajurkar, D. Zhu, B. Wei, Annals of CIRP 47-1 (1998) 165-168.

16. K.P. Rajurkar, D. Zhu, Annals of CIRP 48-1 (1999) 139-142.

17. D. Zhu, K. Wang, Y.M. Yang, CIRP Annals - Manufacturing Technology 52-1 (2003) 169-172.

18. Hihara, Lloyd Hiromi, Panquites IV, Philip, US Pat. 61103512000, (University of Hawaii), 2000.

19. P.J. Ross, Taguchi techniques for quality engineering $-2^{\text {nd }}$ edition, (McGraw-Hill publications, Singapore), 1996. 